\title{
PENGARUH KONSENTRASI DAN LAMA FERMENTASI EKSTRAK BIJI MAHKOTA DEWA (Phaleria macrocarpa) TERHADAP MORTALITAS HAMA KEONG EMAS (Pomacea sp.) DI RUMAH KACA
}

\author{
Lia Septiana, Solikhin \& Agus M. Hariri \\ Jurusan Agroteknologi, Fakultas Pertanian, Universitas Lampung \\ JI. Prof. Dr. Soemantri Brojonegoro No. 1 Bandar Lampung 35145 \\ Email : liaseptiana105@gmail.com
}

\begin{abstract}
ABSTRAK
Penelitian ini bertujuan untuk mempelajari pengaruh taraf konsentrasi dan lama fermentasi ekstrak biji mahkota dewa terhadap mortalitas keong emas dan mengetahui pengaruh interaksi antara konsentrasi dan lama fermentasi ekstrak biji mahkota dewa terhadap mortalitas keong emas. Penelitian ini dilakukan di rumah kaca, Fakultas Pertanian, Universitas Lampung pada bulan Agustus - Oktober 2015. Penelitian disusun dengan rancangan acak kelompok (RAK) faktorial 2 faktor (4 x 3 ). Faktor pertama adalah perlakuan konsentrasi ekstrak biji mahkota dewa yaitu $0 \%\left(\mathrm{~K}_{0}\right), 0,5 \%\left(\mathrm{~K}_{1}\right), 1 \%\left(\mathrm{~K}_{2}\right), 1,5 \%\left(\mathrm{~K}_{3}\right)$. Faktor kedua adalah lama fermentasi ekstrak biji mahkota dewa yaitu fermentasi 5 hari $\left(\mathrm{F}_{5}\right)$, fermentasi 7 hari $\left(\mathrm{F}_{7}\right)$, dan fermentasi 9 hari $\left(\mathrm{F}_{9}\right)$. Data diolah dengan program statistik Microsoft Excel 2007. Homogenitas data diuji dengan Uji Bartlett, dan aditifitasnya diuji dengan Uji Tukey kemudian dilakukan analisis ragam dan dilanjutkan dengan uji Beda Nyata Terkecil (BNT) pada taraf 5\%. Hasil penelitian menunjukkan bahwa terjadi interaksi antara konsentrasi dan lama fermentasi ekstrak biji mahkota dewa yang menyebabkan mortalitas keong emas sebesar 22,5 - 100\%. Aplikasi ekstrak biji mahkota dewa pada konsentrasi $\mathrm{K}_{3}(1,5 \%)$ dan lama fermentasi $\mathrm{F}_{9}(9$ hari) menyebabkan mortalitas keong emas $100 \%$ pada 1 hari setelah aplikasi.
\end{abstract}

Kata kunci: ekstrak biji mahkota dewa, keong emas, mortalitas

\section{PENDAHULUAN}

Padi merupakan komoditas utama bagi masyarakat Indonesia. Karena bahan pangan pokok ini memegang peranan penting dalam kehidupan ekonomi maka setiap faktor yang mempengaruhi tingkat produksinya sangat penting diperhatikan (Sugeng, 2001). Salah satu faktor yang menyebabkan menurunnya produksi padi adalah hama. Hama yang penyebarannya cukup luas dan banyak merusak pertanaman padi adalah keong emas. Keong emas dapat menimbulkan kerusakan tanaman padi 13,2 - 96,5\% (Pitojo, 1996).

Keong emas merupakan spesies yang kosmopolitan yaitu spesies yang distribusinya sangat luas dan mudah beradaptasi, dan merupakan siput air tawar yang berasal dari Amerika Selatan (Min dan Yan, 2006). Hama ini merusak tanaman padi dengan cara memakan bagian pangkal batang sehingga dapat menyebabkan kematian tanaman (Alis, 1997). Perkembangbiakan hama ini sangat cepat sehingga petani kesulitan mengendalikannya. Pengendalian secara mekanis dengan mengambil keong emas yang ada, belum memberikan hasil yang memuaskan. Selain teknik pengendalian secara mekanis yang saat ini telah diterapkan, dipandang perlu dipadukan dengan teknik pengendalian lainnya yang sesuai dengan prinsip prinsip pengendalian hama terpadu (PHT). Salah satu teknik pengendalian yang dikembangkan dalam PHT adalah pemanfaatan bahan tumbuhan sebagai pestisida nabati (Oka, 1994). Salah satu jenis tumbuhan yang dapat dijadikan sebagai bahan pestisida nabati adalah mahkota dewa (Phaleria macrocarpa) (Nugrahaeni, 2011).

Mahkota dewa merupakan salah satu jenis tanaman obat yang dikenal oleh masyarakat Indonesia. Menurut penelitian Sumastuti (2007) menunjukkan bahwa biji mahkota dewa (P. macrocarpa) selain digunakan untuk bahan obat biji mahkota dewa juga dapat digunakan sebagai pestisida nabati, karena biji mahkota dewa mengandung beberapa senyawa berupa alkaloid $0,55 \%$, saponin $20,4 \%$, polifenol $0,23 \%$ dan flavonoid $0,44 \%$. Hal ini dibuktikan oleh penelitian Anggraini (2009) yang menyatakan bahwa ekstrak biji mahkota dewa dengan konsentrasi $0,2 \%$ - 50\% mengakibatkan mortalitas larva Plutella xylostella sebesar 4,04\% - 89,72\%. Selain itu ekstrak biji mahkota dewa juga dinilai potensial sebagai insektisida nabati untuk pengendalian nyamuk Aedes aegypti (Watuguly dan Wilhelmus, 2007). Penelitian ini bertujuan untuk mengetahui pengaruh taraf konsentrasi dan lama 
fermentasi ekstrak biji mahkota dewa terhadap mortalitas keong emas dan mengetahui pengaruh interaksi antara konsentrasi dan lama fermentasi ekstrak biji mahkota dewa terhadap mortalitas keong emas.

\section{BAHAN DAN METODE}

Penelitian ini dilaksanakan di rumah kaca, Fakultas Pertanian, Universitas Lampung pada bulan Agustus sampai Oktober 2015. Alat yang digunakan dalam penelitian ini adalah blender, saringan, ember, gelas ukur, toples kaca, label, timbangan, kamera, kain stimint, sarung tangan, suntikan, jerigen, plastik rafia, dan penggaris. Sedangkan bahan yang digunakan dalam penelitian ini adalah biji buah mahkota dewa (Phaleria macrocarpa), EM4 (Effective microorganism), gula pasir, aquades, keong emas (Pomacea sp.), dan daun talas.

Penelitian disusun secara faktorial 2 faktor (4 $\mathrm{x}$ 3), faktor pertama adalah konsentrasi ekstrak biji mahkota dewa yaitu $0 \%\left(\mathrm{~K}_{0}\right), 0,5 \%\left(\mathrm{~K}_{1}\right), 1 \%\left(\mathrm{~K}_{2}\right)$, dan $1,5 \%\left(\mathrm{~K}_{3}\right)$. Faktor kedua adalah lama fermentasi ekstrak biji mahkota dewa yaitu fermentasi 5 hari $\left(\mathrm{F}_{5}\right)$, fermentasi 7 hari $\left(\mathrm{F}_{7}\right)$, dan fermentasi 9 hari $\left(\mathrm{F}_{9}\right)$. Lama fermentasi ini berdasarkan lanjutan dari hasil penelitian yang dirujuk oleh (Arsyadana, 2014). Perlakuan diterapkan pada satuan percobaan dalam rancangan acak kelompok (RAK). Setelah homogen data diuji dengan Uji Bartlett, dan aditifitasnya diuji dengan Uji Tukey, data dianalisis ragam, dan dilanjutkan dengan uji Beda Nyata Terkecil (BNT) pada taraf 5\%.

Penelitian ini dilakukan melalui beberapa tahapan yaitu: pengumpulan keong emas, pembuatan stok ekstrak biji mahkota dewa (Phaleria macrocarpa), aplikasi ekstrak biji mahkota dewa dan keong emas (Pomacea sp.).

Peubah yang diamati dalam penelitian ini adalah mortalitas keong emas. Mortalitas keong emas dapat dihitung dengan rumus sebagai berikut :

$$
\text { Mortalitas }=\frac{\mathrm{a}}{\mathrm{b}} \times 100 \%
$$

\section{Keterangan:}

$\mathrm{a}=$ Jumlah keong emas yang mati.

$\mathrm{b}=$ Jumlah keong emas yang diinfestasikan pada setiap satuan percobaan.

\section{HASIL DAN PEMBAHASAN}

Hasil penelitian menunjukkan bahwa aplikasi beberapa taraf konsentrasi ekstrak biji mahkota dewa dengan beberapa lama waktu fermentasi (perendaman dengan EM4) nyata menyebabkan mortalitas keong emas. Mortalitas keong emas (Pomacea sp.) yang diakibatkan oleh keracunan ekstrak biji mahkota dewa menunjukkan gejala seperti tidak aktif makan, mengeluarkan lendir dari mulut cangkang, operkulum bewarna coklat kehitaman, dan keluar dari cangkang (Gambar 2).

Mortalitas keong emas (Pomacea sp.) terjadi sejak 1 hari setelah aplikasi ekstrak biji mahkota dewa. Hasil menunjukkan bahwa mortalitas keong emas semakin meningkat dari hari pertama sampai hari ketiga, kecuali pada perlakuan tanpa aplikasi ekstrak biji mahkota dewa tidak terjadi mortalitas atau kematian keong emas. Rata-rata mortalitas keong emas pada masing - masing perlakuan dapat dilihat pada Tabel 1.

Tabel 1 menunjukkan bahwa pada pengamatan 1 hsa sampai 4 hsa semua perlakuan terlihat jelas bahwa semakin tinggi konsentrasi ekstrak biji mahkota dewa dan semakin lama fermentasi maka semakin tinggi dan semakin cepat pengaruhnya terhadap mortalitas keong emas. Hasil penelitian ini juga didukung oleh Shahabudin dan Nur (2013) yang menyatakan penggunaan ekstrak biji mahkota dewa dengan konsentrasi tertinggi $6 \%$ pada 25 HST sudah mampu menekan populasi Spodoptera exigua $94 \%$ serta mampu menurunkan tingkat serangan sebesar $37,6 \%$.

Ekstrak biji mahkota dewa tidak hanya mematikan keong emas tetapi juga

terhadap hama dan serangga lainnya. Apriani (2009) menyatakan bahwa ekstrak biji mahkota dewa konsentrasi 6\% mampu menyebabkan mortalitas larva C. binotalis sebesar $60 \%$. Menurut penelitian Anggraini (2009), konsentrasi ekstrak biji mahkota dewa 50\% dapat mengakibatkan mortalitas larva Plutella xylostella sebesar $89,72 \%$. Shahabuddin dan Nur (2013) mengemukakan bahwa ekstrak biji mahkota dewa $6 \%$ efektif dalam mengendalikan hama Spodoptera exigua dengan tingkat efektivitas sebesar $94 \%$.

Hasil pengamatan mortalitas harian keong emas menunjukkan bahwa perlakuan konsentrasi ekstrak biji mahkota dewa dengan lama fermentasi yang berbeda bersifat toksik terhadap mortalitas keong emas. Pengaruh pemberian konsentrasi ekstrak biji mahkota dewa dengan lama fermentasi yang berbeda terhadap mortalitas keong emas dapat dilihat pada (Gambar 1).

Berdasarkan Gambar 1 tersebut dapat diketahui bahwa pada beberapa taraf konsentrasi ekstrak biji mahkota dewa yang difermentasi selama 5, 7, dan 9 hari terjadi interaksi sehingga menyebabkan mortalitas keong emas. Hal ini terlihat bahwa pada perlakuan $\mathrm{K}_{3} \mathrm{~F}_{9}$ (1,5\% dengan lama fermentasi 9 hari) sudah terjadi mortalitas keong emas pada 1 hari setelah aplikasi. Hal 
Tabel 1. Rata-rata mortalitas keong emas dengan pemberian beberapa konsentrasi ekstrak biji mahkota dewa (Phaleria macrocarpa) dan beberapa lama waktu fermentasi.

\begin{tabular}{lrlrlrlrl}
\hline \multirow{2}{*}{ Perlakuan } & \multicolumn{7}{c}{ Mortalitas keong emas (\%) pada } \\
\cline { 2 - 8 } & $1 \mathrm{HSA}$ & $2 \mathrm{HSA}$ & $3 \mathrm{HSA}$ & $4 \mathrm{HSA}$ \\
\hline $\mathrm{K}_{0} \mathrm{~F}_{5}$ & 0,00 & $\mathrm{a}$ & 0,00 & $\mathrm{a}$ & 0,00 & $\mathrm{a}$ & 0,00 & $\mathrm{a}$ \\
$\mathrm{K}_{1} \mathrm{~F}_{5}$ & 40,00 & $\mathrm{c}$ & 65,00 & $\mathrm{~b}$ & 85,00 & $\mathrm{~b}$ & 92,50 & $\mathrm{~b}$ \\
$\mathrm{~K}_{2} \mathrm{~F}_{5}$ & 65,00 & ef & 77,50 & $\mathrm{c}$ & 95,00 & $\mathrm{c}$ & 100,00 & $\mathrm{c}$ \\
$\mathrm{K}_{3} \mathrm{~F}_{5}$ & 65,00 & ef & 82,50 & $\mathrm{~cd}$ & 100,00 & $\mathrm{c}$ & 100,00 & $\mathrm{c}$ \\
$\mathrm{K}_{0} \mathrm{~F}_{7}$ & 0,00 & $\mathrm{a}$ & 0,00 & $\mathrm{a}$ & 0,00 & $\mathrm{a}$ & 0,00 & $\mathrm{a}$ \\
$\mathrm{K}_{1} \mathrm{~F}_{7}$ & 22,50 & $\mathrm{~b}$ & 75,00 & $\mathrm{bc}$ & 87,50 & $\mathrm{~b}$ & 100,00 & $\mathrm{c}$ \\
$\mathrm{K}_{2} \mathrm{~F}_{7}$ & 57,50 & $\mathrm{de}$ & 90,00 & $\mathrm{de}$ & 100,00 & $\mathrm{c}$ & 100,00 & $\mathrm{c}$ \\
$\mathrm{K}_{3} \mathrm{~F}_{7}$ & 72,50 & $\mathrm{f}$ & 100,00 & $\mathrm{e}$ & 100,00 & $\mathrm{c}$ & 100,00 & $\mathrm{c}$ \\
$\mathrm{K}_{0} \mathrm{~F}_{9}$ & 0,00 & $\mathrm{a}$ & 0,00 & $\mathrm{a}$ & 0,00 & $\mathrm{a}$ & 0,00 & $\mathrm{a}$ \\
$\mathrm{K}_{1} \mathrm{~F}_{9}$ & 50,00 & $\mathrm{~cd}$ & 92,50 & $\mathrm{de}$ & 100,00 & $\mathrm{c}$ & 100,00 & $\mathrm{c}$ \\
$\mathrm{K}_{2} \mathrm{~F}_{9}$ & 85,00 & $\mathrm{~g}$ & 100,00 & $\mathrm{e}$ & 100,00 & $\mathrm{c}$ & 100,00 & $\mathrm{c}$ \\
$\mathrm{K}_{3} \mathrm{~F}_{9}$ & 100,00 & $\mathrm{~h}$ & 100,00 & $\mathrm{e}$ & 100,00 & $\mathrm{c}$ & 100,00 & $\mathrm{c}$ \\
\hline
\end{tabular}

Keterangan: Angka sekolom yang diikuti huruf yang sama tidak berbeda nyata menurut uji BNT pada taraf $5 \%$. HSA $=$ Hari setelah aplikasi. $\mathrm{K}_{0} \mathrm{~F}_{5}=$ Tanpa ekstrak biji mahkota dewa. $\mathrm{K}_{1} \mathrm{~F}_{5}=$ Konsentrasi ekstrak biji mahkota dewa $0,5 \%$ dengan fermentasi 5 hari. $\mathrm{K}_{2} \mathrm{~F}_{5}=$ Konsentrasi ekstrak biji mahkota dewa $1 \%$ dengan fermentasi 5 hari. $\mathrm{K}_{3} \mathrm{~F}_{5}=$ Konsentrasi ekstrak biji mahkota dewa 1,5\% dengan fermentasi 5 hari. $\mathrm{K}_{0} \mathrm{~F}_{7}=$ Tanpa ekstrak biji mahkota dewa. $\mathrm{K}_{1} \mathrm{~F}_{7}=$ Konsentrasi ekstrak biji mahkota dewa 0,5\% dengan fermentasi 7 hari. $\mathrm{K}_{2} \mathrm{~F}_{7}=$ Konsentrasi ekstrak biji mahkota dewa $1 \%$ dengan fermentasi 7 hari. $\mathrm{K}_{3} \mathrm{~F}_{7}=$ Konsentrasi ekstrak biji mahkota dewa 1,5\% dengan fermentasi 7 hari. $\mathrm{K}_{0} \mathrm{~F}_{9}=$ Tanpa ekstrak biji mahkota dewa. $\mathrm{K}_{1} \mathrm{~F}_{9}=$ Konsentrasi ekstrak biji mahkota dewa $0,5 \%$ dengan fermentasi 9 hari. $\mathrm{K}_{2} \mathrm{~F}_{9}=$ Konsentrasi ekstrak biji mahkota dewa $1 \%$ dengan fermentasi 9 hari. $\mathrm{K}_{3} \mathrm{~F}_{9}=$ Konsentrasi ekstrak biji mahkota dewa 1,5\% dengan fermentasi 9 hari.

ini dikarenakan semakin tinggi konsentrasi dan semakin lama fermentasi maka semakin pekat ekstrak biji mahkota dewa sehingga semakin tinggi mortalitas keong emas uji. Hal ini sesuai dengan pendapat Rusdy (2010) yang menyatakan semakin tinggi tingkat kepekatan ekstrak pestisida nabati maka semakin tinggi daya bunuhnya.

Berdasarkan hasil pengamatan memperlihatkan bahwa pada saat keong emas bergerak untuk mencari makan mengakibatkan terjadinya kontak tubuh dengan ekstrak biji mahkota dewa yang telah diaplikasi pada media uji. Menurut Musman et al. (2011), keong emas bergerak mencari makan dengan cara membuka operculum dan menggerakkan kakinya. Sehingga ekstrak biji mahkota dewa terakumulasi pada kaki keong emas yang menyebabkan keluarnya lendir dari tubuh keong emas. Keluarnya lendir dalam jumlah yang berlebihan maka secara tidak langsung dapat menghambat proses pernapasan keong emas dan

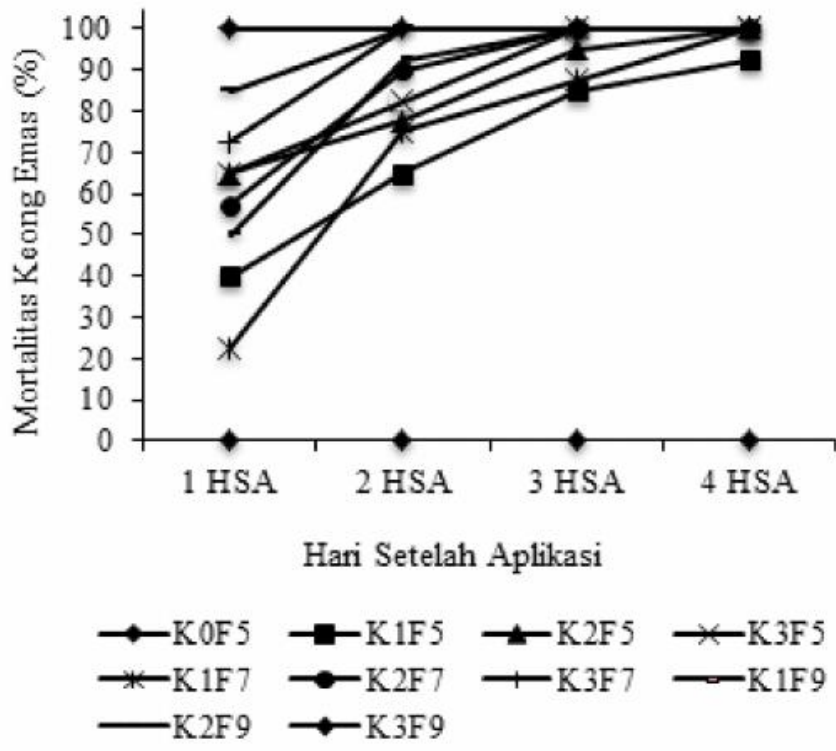

Gambar 1. Mortalitas harian keong emas (Pomacea sp.) 

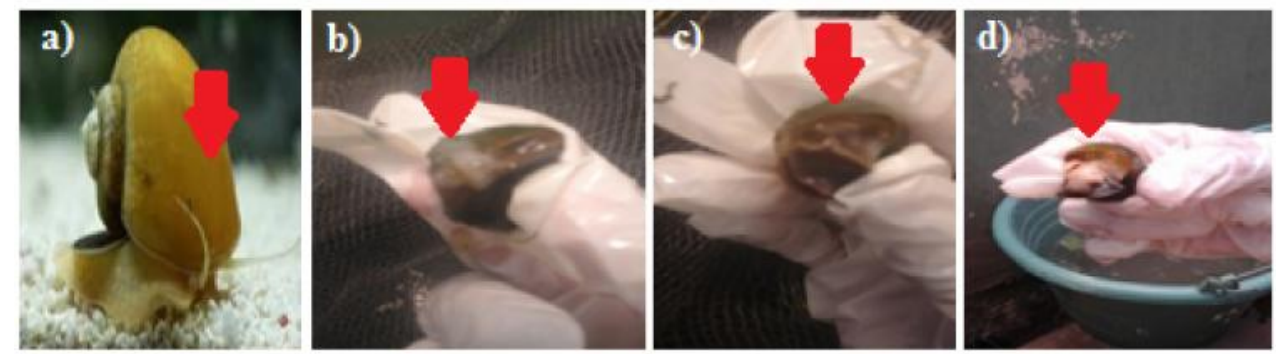

Gambar 2. Keong emas masih sehat (a), keong emas mengeluarkan lendir (b), operculum keong emas menjadi kaku bewarna coklat kehitaman (c), tubuh keong emas keluar dari cangkang (d).

mengakibatkan kematian yang ditandai dengan operculum menjadi kaku serta bewarna coklat kehitaman (Gambar 2).

Lendir yang keluar dari tubuh keong emas diduga diakibatkan oleh reaksi tubuh keong emas yang terinfeksi oleh senyawa racun yang terdapat dalam ekstrak biji mahkota dewa. Kandungan saponin yang ada dalam biji mahkota dewa bersifat toksik, sehingga menyebabkan terlepasnya tubuh keong emas dari cangkangnya kemudian berakhir dengan kematian. Kematian keong emas tersebut menimbulkan bau busuk pada saat pengamatan. Hasil penelitian ini didukung oleh Laoh et al. (2013) yang menyatakan bahwa semakin banyak senyawa kimia dari pestisida nabati yang masuk kedalam tubuh keong emas maka akan semakin banyak jaringan tubuh keong emas yang rusak. Akibatnya pergerakan menjadi lamban, nafsu makan berkurang, mengeluarkan lendir dan tubuh keluar dari cangkang yang berakhir dengan kematian. Perubahan keong emas setelah terinfeksi ekstrak biji mahkota dewa dapat dilihat pada (Gambar 2).

Menurut hasil penelitian Soeksmanto et al. (2007), senyawa kimia yang terdapat dalam biji mahkota dewa mengandung senyawa saponin yang merupakan larutan berbuih yang diklasifikasikan sebagai struktur streroid saponin. Senyawa tersebut bersifat racun kontak dan racun perut.

Penelitian Haryanti et al. (2006) yang menggunakan serangga uji ulat grayak, menyatakan bahwa kandungan saponin yang terkandung dalam ekstrak etanol biji mahkota dewa mampu meracuni ulat grayak (Spodoptera litura) sebagai racun kontak dan racun perut. Dalam waktu 6 hari setelah aplikasi ekstrak etanol biji mahkota dewa dengan LC95 mampu membunuh $100 \%$ ulat grayak instar 2 . Selaras dengan penelitian Okta (2009) yang menyatakan bahwa pemberian ekstrak biji mahkota dewa menyebabkan mortalitas pada larva P. xylostella. Persentase kematian P. xylostella semakin meningkat pada konsentrasi yang semakin besar. Pada konsentrasi tertinggi yaitu 50\% ekstrak biji mahkota dewa mengakibatkan kematian larva P. xylostella sebesar $89,72 \%$. Selanjutnya pada konsentrasi ekstrak biji mahkota dewa $0,2,0,78,3,12$, dan $12,5 \%$ mortalitas larva $P$. xylostella yang terjadi berturut - turut adalah 4,04, 30,59, 38,80, dan 75,52\%.

Selain menggunakan ekstrak biji mahkota dewa sebagai pestisida nabati, telah banyak diketahui dari jenis tumbuhan lain yang juga memiliki kandungan senyawa kimia yang mampu mengendalikan keong emas. Berdasarkan penelitian Rusdy (2010), pada perlakuan bawang putih $20 \mathrm{ml}$ ekstrak bawang yang di campur dengan $80 \mathrm{ml}$ air menyebabkan semakin singkat waktu yang dibutuhkan untuk mengendalikan atau mematikan keong emas. Kurniawati et al. (2015) menyatakan bahwa ekstrak brotowali dengan konsentrasi $75 \mathrm{~g} / \mathrm{l}$ air merupakan konsentrasi yang mampu mengendalikan keong emas (Pomacea sp.) dengan waktu awal kematian 12 jam setelah aplikasi, LT 28,25 jam dan mortalitas total sebesar $86,99 \%$. Laoh et al. (2013) menyatakan bahwa aplikasi dosis tepung biji pinang pada perlakuan $0,8 \%$ mampu menyebabkan mortalitas hama keong emas sampai $87,49 \%$. Selanjutnya menurut Wibowo et al. (2008) menyatakan bahwa aplikasi ekstrak kasar daun nimba $4 \mathrm{~g} / 1$ menyebabkan mortalitas keong emas sebesar $100 \%$ pada 96 jam setelah aplikasi.

\section{KESIMPULAN}

Berdasarkan hasil penelitian dapat disimpulkan bahwa ekstrak biji mahkota dewa pada kisaran konsentrasi 0,5 - 1,5\% menyebabkan mortalitas keong emas. Konsentrasi 1,5\% mampu menyebabkan $100 \%$ mortalitas keong emas uji pada 1 hari setelah aplikasi. Ekstrak biji mahkota dewa pada konsentrasi 0,5 - 1,5\% yang difermentasi dengan larutan EM4 selama 9 hari dapat menimbulkan mortalitas $100 \%$ keong emas uji pada 3 hari setelah aplikasi. Terjadinya interaksi antara konsentrasi dan lama fermentasi ekstrak biji mahkota 
dewa menyebabkan mortalitas keong emas hingga mencapai $100 \%$.

\section{DAFTAR PUSTAKA}

Alis F. 1997. Pertumbuhan keong emas (Pomacea sp.) yang diberi pakan beberapa jenis tumbuhan. Skripsi. Institut Pertanian Bogor.

Anggraini O.D. Uji Efektivitas Ekstrak Mahkota Dewa (Phaleria papuena Warb.) terhadap Mortalitas Ulat Daun Kubis (Plutella xylostella L.) pada Tanaman Caisin (Ed.). Mei. 2009. Available online at http://dglib.uns.ac.id/pengguna.php? mn=detail \&d_id=9472, [26 Agustus 2015].

Apriani E. Uji Efektivitas Ekstrak Mahkota Dewa (Phaleria papuena Warb.) terhadap Mortalitas (Crocidolomia binotalis) pada Tanaman Caisin (Ed.). Mei 2009. Available online at http:// dgli.uns.ac.id/pengguna.php?mn=detail \& d_id=9591, [19 Agustus 2015].

Arsyadana. 2014. Efektivitas biopestisida biji mahkota dewa (Phaleria macrocarpa) dengan lama fermentasi yang berbeda untuk mengendalikan hama keong emas (Pomacea canaliculata) pada tanaman padi (Oryza sativa). Skripsi. Universitas Muhammadiyah. Surakarta.

Haryanti, M. Suryana, \& Nurrahman. Uji Daya Insektisida Ekstrak Etanol 70\% Biji Buah Mahkota Dewa (Phaleria macrocarpa (Scheff.) Boerl) terhadap Ulat Grayak (Spodoptera litura (Fab) Instar Dua di Balai Besar Litbang Tanaman Obat dan Obat Tradisional (Ed.). Available online at http://www.litbang. depkes.go.id., [18 Desember 2015].

Kurniawati, D., R. Rusli, dan J. H. Laoh. 2015. Pemberian Beberapa Konsentrasi Ekstrak Brotowali (Tinospoa crispa L.) untuk Mengendalikan Keong Emas (Pomacea sp.) pada Tanaman Padi (Oryza sativa L). J. Jom. Faperta. 2(1): 1-8.

Laoh, J.H., R. Rusli, dan P. Riadi. 2013. Pemberian Beberapa Dosis Tepung Biji Pinang (Areca catechu L.) Lokal Riau untuk Mengendalikan Hama Keong Emas (Pomacea canaliculata L.) pada Tanaman Padi. J. Hama Tropika. 1(2): $2-8$.
Min, W. dan X. Yan. 2006. The Golden Apple Snail (Pomacea canaliculata) in China, hlm: 285 289. In: Jo Shi RC and Sebastian LS. (eds.), Global Advances in Ecology and Management of Golden Apple Snails. Phil Rice. Ingeneria.

Musman, M., F. Sofia, dan V. Kurnianda. 2011. Selektifitas Fraksi Rf <0,5 Ekstrak Etil Asetat (EtOAc) Biji Putat Air (Barringtonia racemosa) terhadap Keong Emas (Pomacea canaliculata) dan Ikan Lele Lokal (Clarias batracus). J. Depik. 1(2): 99-102.

Nugrahaeni F. 2011. Efektivitas ekstrak biji mahkota dewa (Phaleria macrocarpa) dan ekstrak biji bengkuang (Pachyrhizus erocus) dalam pngendalian hama buah kakao. Skripsi. Universitas Sebelas Maret.

Oka, I. N. 1994. Pengendalian Hama Terpadu dan Implementasinya di Indonesia. UGM Press. Yogyakarta.

Okta. 2009. Uji efektivitas ekstrak mahkota dewa (phaleria papuena Warb.) terhadap mortalitas ulat daun kubis (Plutella xylostella L.) pada tanaman caisin. Skripsi. Universitas Sebelas Maret. Surakarta.

Pitojo S. 1996. Petunjuk Pengendalian dan Pemanfaatan Keong Emas. PT Trubus Agriwidya. Ungaran. $106 \mathrm{hlm}$.

Rusdy, A. 2010. Pengaruh Pemberian Ekstrak Bawang Putih terhadap Mortalitas Keong Emas. J. Floratek. 5(2): 172 - 180.

Shahabuddin \& K Nur. 2013. Efektivitas Ekstrak Biji Mahkota Dewa (Phaleria papuena Warb.) dalam Mengendalikan Hama (Spodoptera exigua Hubner) (Lepidoptera: Noctuidae) pada Pertanaman Bawang Merah. J. Agroland. 17(3): 21-27.

Soeksmanto, A, Y. Hapsari, dan P. Simanjuntak. 2007. Kandungan Antioksidan pada Beberapa Bagian Tanaman Mahkota Dewa (Phaleria macrocarpa) (Scheff) Boerl) (Thymelaceae). J. Biodiversitas. 8(2): 92-95.

Sugeng, H. 2001. Bercocok Tanam Padi. Aneka Ilmu. Semarang. $64 \mathrm{hlm}$.

Sumastuti. Mahkota dewa (Ed.). Available online at http://www.Tanamanherbal.wordpress.com., [20 Agustus 2015] 
Watuguly dan Wilhelmus. Uji Toksisitas Bioinsektisida Ekstrak Biji Mahkota Dewa (Phaleria papuana Warb.) terhadap Mortalitas Nyamuk (Aedes aegypti L.) di Laboratorium (Ed.). Available online at http://www.adln.lib.unair.ac.id., [21 Agustus 2015].
Wibowo, L, Indriyati, dan Solikhin. 2008. Uji Aplikasi Ekstrak Kasar Buah Pinang, Akar Tuba, Patah Tulang, dan Daun Nimba terhadap Keong Emas (Pomacea sp.) di Rumah Kaca. J. HPT Tropika. 8(1): 17-22. 